\title{
Retinal macroaneurysms
}

\author{
P. E. CLEARY*, E. M. KOHNER $\dagger$, A. M. HAMILTON*, AND A. C. BIRD* \\ From the *Retinal Unit, Department of Clinical Ophthalmology, Institute of Ophthalmology, Moorfields Eye Hospital, \\ London and the $\nmid$ Royal Postgraduate Medical School, Hammersmith Hospital, Du Cane Road, London Wi 4
}

Several reports of isolated aneurysms on the retinal arteries appeared in the ophthalmic literature early in this century (Pringle, 1917; Jennings, 1918; Fernandez, 1920). The retinal artery aneurysms described by Reimar (1899) and Raehlmann (1889, 1902) were typically seen in elderly patients with atheromatous vascular degeneration, and the $36-$ year-old patient reported by Ballantyne (1937) had severe uncontrolled hypertension.

More recently, Robertson (1973) introduced the term macroaneurysm to describe an aneurysm arising on a main retinal artery within the first three orders of bifurcation. He described 13 patients in whom the macroaneurysms were frequently accompanied by local haemorrhage and exudates producing scotomas and impairment of macular vision, but he emphasized the natural tendency for aneurysms to heal spontaneously. On the other hand Hudomel and Imre (1973) reported a case of a solitary aneurysm causing progressive central visual loss over a i 2-month period. A further 5 patients have since been reported by Schults and Swan (1974). The aneurysm pulsated spontaneously in 3 of these, all of which subsequently bled, and they concluded that the presence of pulsation may indicate impending vessel rupture and serious bleeding.

Important factors in the aetiology of macroaneurysms would appear to be ageing, hypertension, and arteriosclerosis which were present in many of the patients described.

The purpose of this report is to describe the appearance, the natural history, and the systemic associations of these lesions.

\section{Patients and methods}

During a 4-year period 20 patients with retinal macroaneurysms have been examined in the Retinal Unit at Moorfields Eye Hospital and the evolution of the lesions has been documented with photographs for at least 9 months in each case. The macroaneurysms conformed to the criteria as defined by Robertson. Patients who had aneurysms such as 'berries on a stalk' as described by Leber (1915), venous aneurysms, capillary aneurysms, and multiple aneurysmal dilatations were excluded.

Address for reprints: A. C. Bird, MD, FRCS, Retinal Unit, Moorfields Eye Hospital, City Road, London EC1V 2PD
Eighteen of the patients were examined for evidence of hypertension and systemic vascular disease (the two not included were those who died). The blood pressure was considered elevated if the systemic pressure was above $160 \mathrm{~mm} \mathrm{Hg}$ or if the diastolic pressure was above 100 $\mathrm{mm} \mathrm{Hg}$. Laboratory investigations included chest $x$ ray and electrocardiagram (ECG). All patients had blood taken for a full blood count, serological tests for syphilis, and measurement of urea, uric acid, electrolytes, blood sugar (glucose tolerance test if under 65 years of age), fasting cholesterol, triglycerides, and lipoprotein electrophoresis. The upper limit of normal cholesterol is 240 $\mathrm{mg} / \mathrm{I} 00 \mathrm{ml}$ and of triglycerides $150 \mathrm{mg} / 100 \mathrm{ml}$ in our laboratory.

\section{Results}

Altogether 27 macroaneurysms were documented in the 20 patients. A single macroaneurysm was observed in I 4 patients; 2 macroaneurysms in one eye in 3, and 5 macroaneurysms in one eye in one patient. A further patient had a single macroaneurysm in each eye. More than one aneurysm on the same artery was found in only 2 cases: 3 macroaneurysms on a single artery in one and 2 in the other.

The presenting symptom in 19 patients was loss of central vision. This was the result of a macular haemorrhage in 12 patients, of a vitreous haemorrhage in I patient, and of macular oedema in the other 6. In one remaining patient a macroaneurysm was found at a routine ophthalmological examination.

The haemorrhage from a retinal macroaneurysm was typically dense, intraretinal, and at least a disc diameter in size (Fig. $1 a$ ). The aneurysm in the centre of the haemorrhage was obscured by blood to a varying extent. In 3 patients the haemorrhage was preretinal and in 2 others subretinal. Vitreous haemorrhage occurred as a result of aneurysmal rupture in only one case, and in this patient the aneurysm had been noted previously to pulsate. Immediately after haemorrhage, blood obscured the vascular detail on fluorescein fundus angiography but dye leakage from the aneurysm was detectable during the later stages of the angiogram in all cases (Fig. $1 b$ ).

Absorption of haemorrhage occurred over a 6 to 8 week period and the vision returned to normal in 7 of the 12 patients who presented with macular hae- 

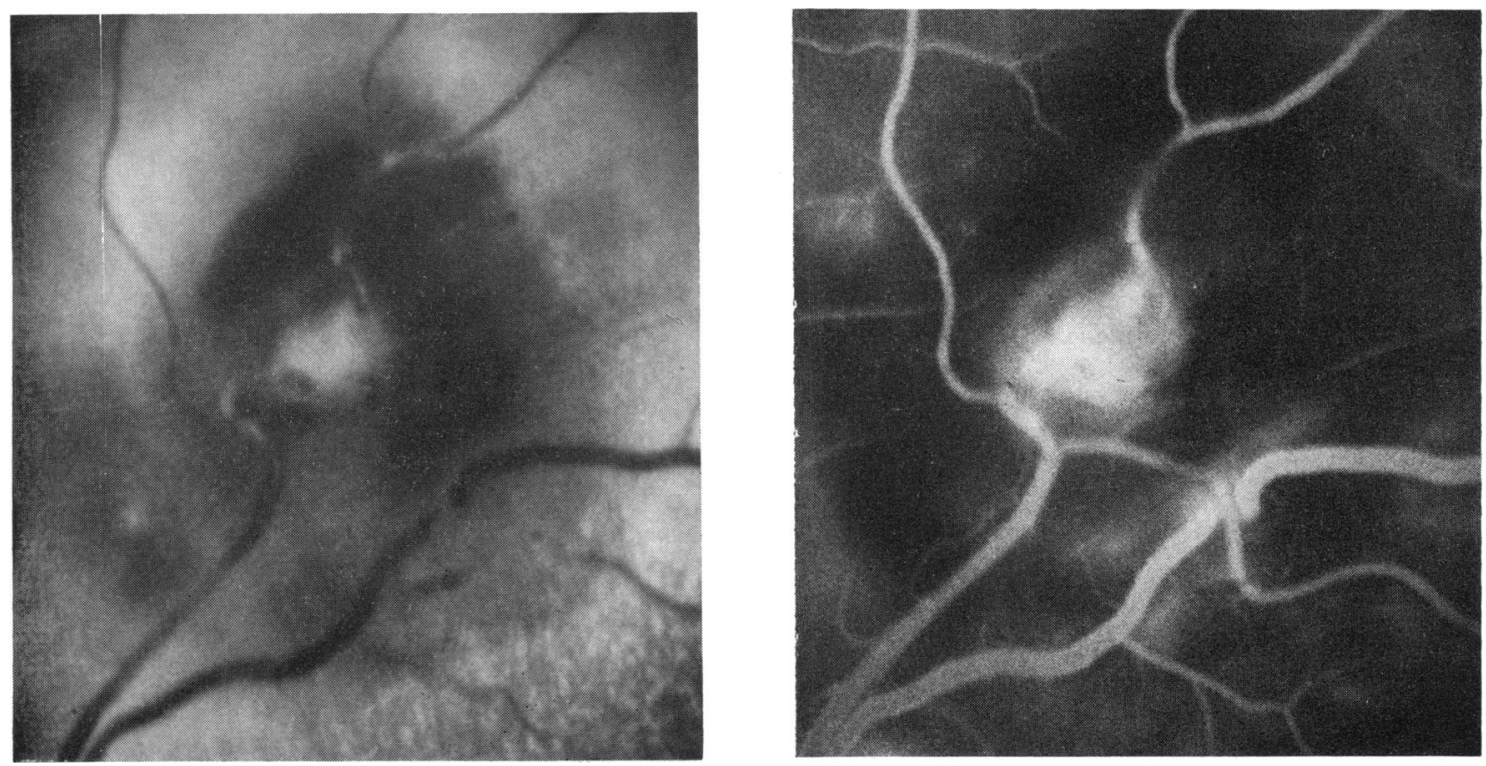

F I G. I Case 5. Macroaneurysm surrounded by dense intraretinal haemorrhage ( 1 a). Fluorescein angiogram demonstrates leakage from macroaneurysm and arterio-venous crossing change $(\mathrm{I} b)$

morrhage and in the patient with the vitreous haemorrhage. Incomplete visual recovery in the other 5 patients with macular haemorrhage was attributable to the presence of preretinal fibrosis (one case), persistence of blood (one case), pigment epithelial changes at the macula (two cases), and macular arterial occlusion (one case).

After absorption of intraretinal haemorrhage the retina appeared normal but after absorption of subretinal haemorrhage there was disturbance of the pigment epithelium (one case) and a white fibrous subretinal scar (one case).

Macular oedema and intraretinal exudates occurred

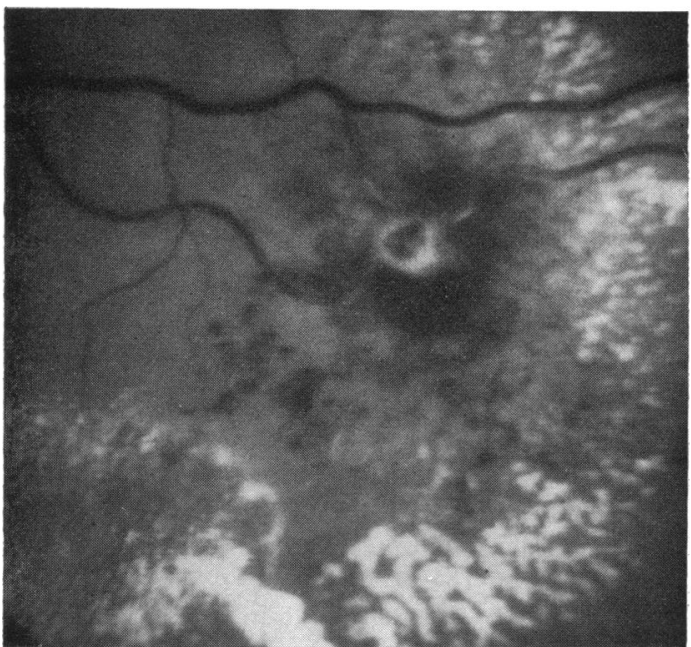

in the absence of haemorrhage in 6 cases. The intraretinal exudates surrounded the aneurysm or were distributed at the macula (Fig. 2a). Fluorescein fundus angiography demonstrated diffuse leakage of dye through the wall of the aneurysm and from dilated macular capillaries (Fig. 2b). In 3 patients leakage of dye was also demonstrated from dilated retinal capillaries surrounding the aneurysm. The oedema and intraretinal exudates persisted during the period of observation even in 2 patients in whom the macroaneurysm fibrosed (Fig. $2 c, d$ ) and there was a considerable reduction in central vision in all patients, the best visual acuity attained being 6/24. In I

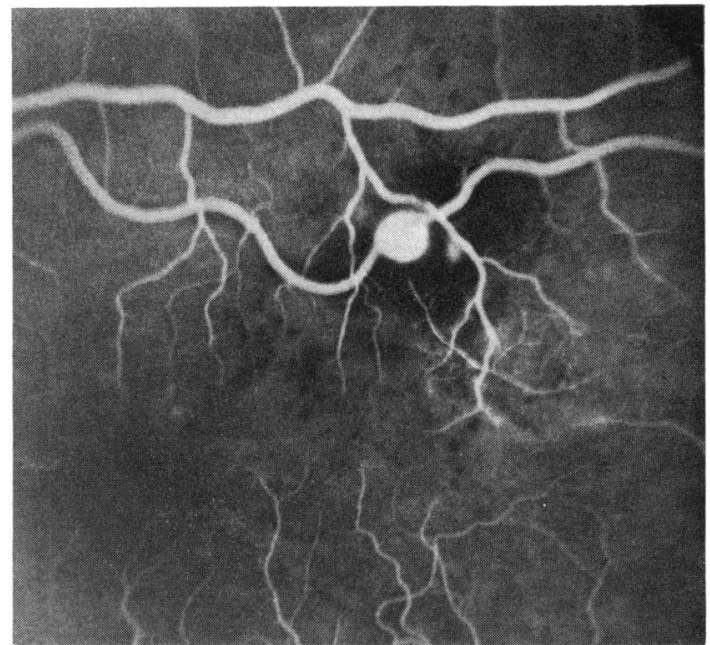

F I G. 2 Case 20. Macroaneurysm causing macular oedema and intraretinal exudates (2a). Fluorescein angiography reveals a patent leaking macroaneurysin and dilated macular capillaries $(2 b)$. 

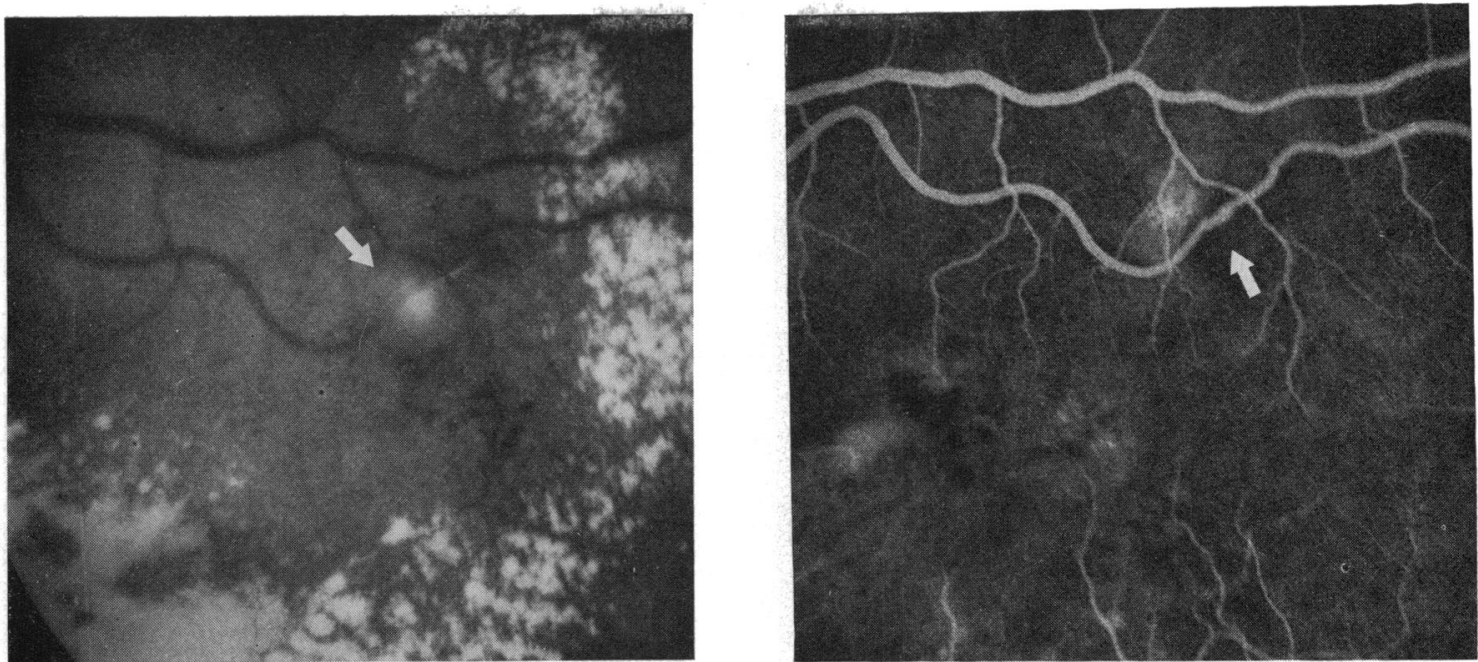

Six months later macroaneurysm has fibrosed (arrow) but macular oedema and intraretinal exudates have persisted (2c). The fluorescein angiogram shows that aneurysm is no longer patent but site may be identified by irregularity of arterial lumen (arrow), and there is leakage of dye from dilated macular capillaries $(2 d)$
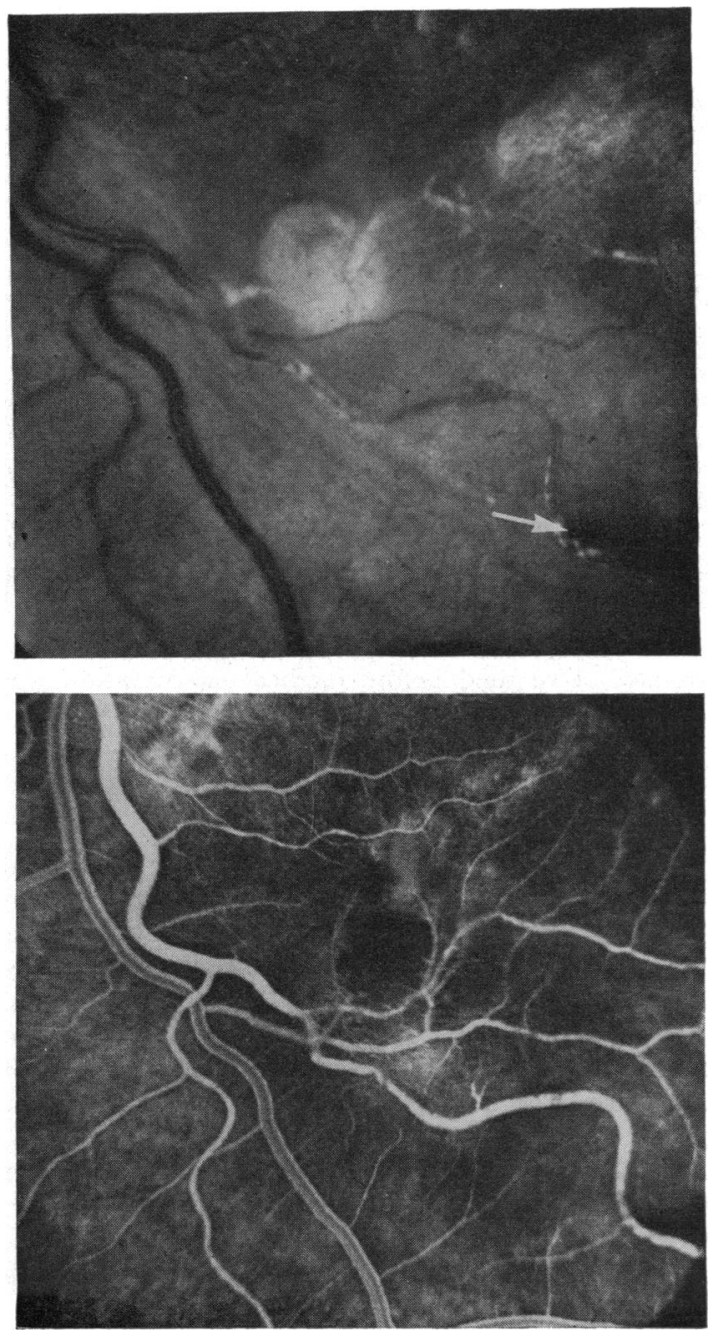

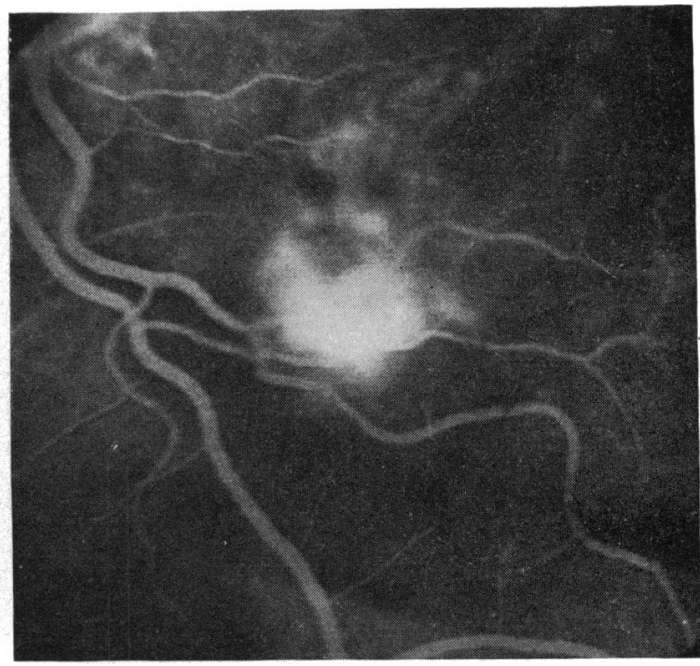

FI G. 3 Case Io. Large fibrosed macroaneurysm associated with preretinal fibrous tissue at macula. There is some residual preretinal haemorrhage (arrow) ( $3 a)$. Fluorescein angiogram reveals attenuation of involved artery and dilated retinal capillaries surrounding macroaneurysm $(3 b)$. Fluorescein angiography in later stages demonstrates leakage from dilated capillaries and staining of wall of macroaneurysm (3c)

patient a coexistent second order retinal branch vein occlusion contributed to the macular oedema.

In all 13 patients in whom there was haemorrhage, bleeding was followed by closure of the macroaneurysm, but closure occurred in only 2 of the 6 patients with macular oedema. In the I patient in whom the macroaneurysm was not associated with previous haemorrhage or oedema resolution occurred when the aneurysm fibrosed and the artery occluded. A fibrosed macroaneurysm (Fig. $3 a, b, c$ ) was observed in all but 4 of the cases that resolved and in these 4 the site of the aneurysm could be identified by a slight kink- 
ing or localized constriction of the arterial lumen (Fig. $4 a, b, c)$. Sheathing of the involved artery was present in 6 cases of which 5 were shown to be occluded by fluorescein fundus angiography (Fig. $5 a, b$ ) but even when arterial occlusion did not accompany resolution the affected artery was attenuated and its lumen irregular distal to the aneurysm.

All patients in this study had generalized retinal vascular disease with attenuated and irregular arteries, and arterio-venous crossing changes. The presence of a retinal branch vein occlusion in the same or fellow eye of 5 patients and a branch arterial occlusion in 2 emphasized the presence of coexistent retinal vascular disease.

The results of the main medical abnormalities found are presented in the Table.

Of the 13 patients with hypertension, only 5 were on treatment at the time of the examination and in 2 of these the blood pressure was inadequately con-

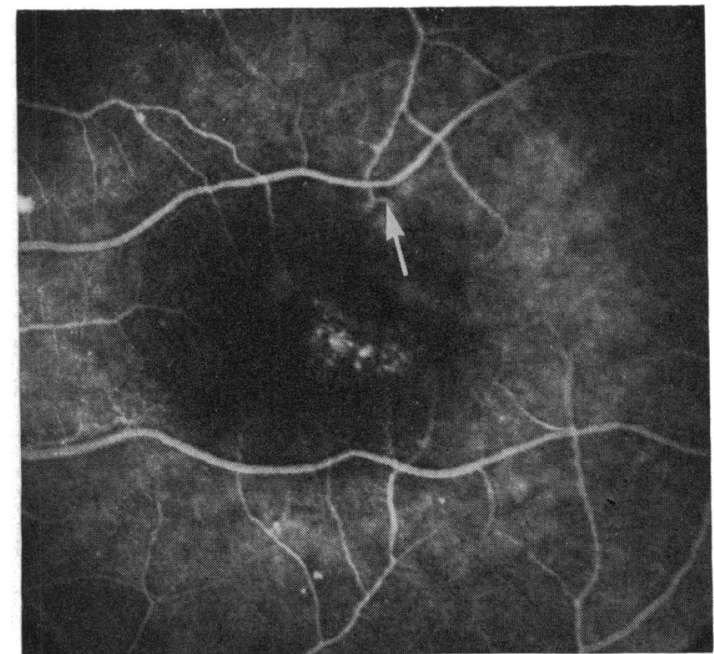

FIG. 4 Case 3. Typically dense haemorrhage from macroaneurysm; aneurysm is just visible in centre of haemorrhage (4a). Fluorescein angiogram shows leakage from macroaneurysm $(4 b)$. Twelve months later haemorrhage has absorbed and on fluorescein angiogram lumen of involved artery is slightly kinked and irregular at site of macroaneurysm (arrow); pigment epithelial changes at macula have caused transmission defects $(4 c)$

trolled. In 3 normotensive patients previous myocardial infarction may have accounted for the normal blood pressure.

Nine patients had abnormal lipid levels and lipoprotein electrophoresis. It is of interest that only 2 of these had a raised serum uric acid and this may be because of the age of the patients.

The blood count was within normal limits, and the serological tests for syphilis were negative in all the patients.

All the patients had some evidence of vascular disease. Two died before medical examination was carried out, one from a myocardial infarct, the other from a cerebrovascular accident.

\section{Discussion}

Retinal macroaneurysms constitute a distinct clinical entity which is seen in elderly people with hypertension of generalized vascular disease. Similar aneurysms have been described on cerebral arteries in precisely similar patients (Ross Russell, 1963; Cole and Yates, 1967). The cerebral arteries involved were of the same size as the main retinal arteries but retinal arteries differ in having an unusually developed muscularis. However, with ageing and arteriosclerosis, retinal arteries lose their muscle coat becoming thin walled and fibrotic. In this state they may easily dilate with increased intraluminal pressure (Leishman, 1957), thus resembling cerebral arteries. In the walls of intracerebral aneurysms the endothelium was 

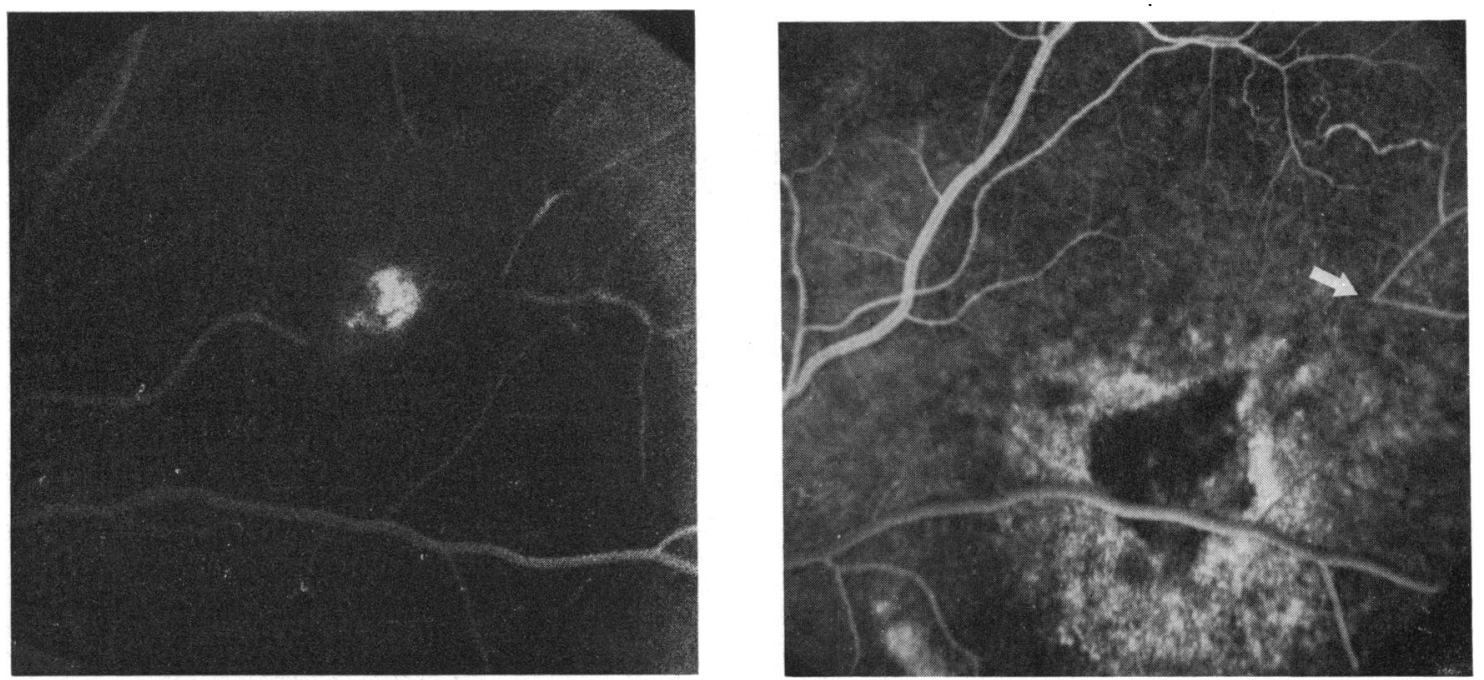

F I G. 5 Case 8. Fluorescein angiogram shows leakage from macroaneurysm associated with subretinal haemorrhage ( 5 a). Haemorrhage has absorbed and fluorescein angiogram demonstrates occlusion of involved artery with retrograde filling of its distal branches (arrow); subretinal pigment masks background choroidal fluorescence $\left(5^{b}\right)$

Table

\begin{tabular}{|c|c|c|c|c|}
\hline Case & $\begin{array}{l}\text { Sex } \\
\text { and age } \\
\text { (yrs) }\end{array}$ & $\begin{array}{l}\text { Initial } \\
\text { visual acuity }\end{array}$ & $\begin{array}{l}\text { Present } \\
\text { visual acuity }\end{array}$ & Systemic disease \\
\hline$I$ & $\begin{array}{l}\text { Male } \\
66\end{array}$ & $6 / 6$ & $6 / 6$ & $\begin{array}{l}\text { Hypertension } \\
\text { Elevated serum cholesterol and } \\
\text { triglycerides } \\
\text { Lipoprotein electrophoresis } \\
\text { Type II B } \\
\text { Raised serum uric acid } \\
\end{array}$ \\
\hline 2 & $\begin{array}{l}\text { Male } \\
73\end{array}$ & $6 / 3^{6}$ & $6 / 3^{6}$ & $\begin{array}{l}\text { Hypertension with evidence } \\
\text { of myocardial ischaemia on } \\
\text { electrocardiogram }\end{array}$ \\
\hline 3 & $\begin{array}{l}\text { Female } \\
64\end{array}$ & $\overline{\mathrm{CF}}$ & $\overline{\mathrm{CF}}$ & $\begin{array}{l}\text { Hypertension } \\
\text { Two previous cerebrovascular } \\
\text { accidents } \\
\text { Elevated serum cholesterol } \\
\text { and triglycerides } \\
\text { Lipoprotein electrophoresis } \\
\text { Type II A }\end{array}$ \\
\hline 4 & $\begin{array}{l}\text { Male } \\
65\end{array}$ & $\overline{\mathrm{CF}}$ & $6 / 9$ & $\begin{array}{l}\text { Previous myocardial infarction } \\
\text { Elevated serum cholesterol and } \\
\text { triglycerides } \\
\text { Lipoprotein electrophoresis } \\
\text { Type II A }\end{array}$ \\
\hline 5 & $\begin{array}{l}\text { Female } \\
79\end{array}$ & $6 / 3^{6}$ & $6 / 9$ & $\begin{array}{l}\text { Hypertension and intermittent } \\
\text { claudication } \\
\text { Elevated serum cholesterol } \\
\text { and triglycerides } \\
\text { Lipoprotein electrophoresis } \\
\text { Type III } \\
\text { Raised serum uric acid }\end{array}$ \\
\hline 6 & $\begin{array}{l}\text { Male } \\
7 \mathrm{I}\end{array}$ & $\overline{\mathrm{CF}}$ & $\overline{6 / 6}$ & $\begin{array}{l}\text { Hypertension } \\
\text { Right bundle branch block }\end{array}$ \\
\hline
\end{tabular}

Ophthalmoscopic finding

Single aneurysm which did not bleed or leak and closed spontaneously with occlusion of artery

Intraretinal haemorrhage

Single macroaneurysm which fibrosed

Pigment epithelial changes at macula

Intraretinal haemorrhage

Single macroaneurysm which fibrosed

Pigment epithelial changes at macula

Retinal branch vein occlusion in fellow eye

Preretinal haemorrhage

Single macroaneurysm which fibrosed

\section{Intraretinal haemorrhage in right eye from a single macroaneurysm which fibrosed \\ Asymptomatic leaking aneurysm in inferior nasal quadrant of left eye \\ Retinal branch vein occlusion \\ Intraretinal haemorrhage \\ Single macroaneurysm which did not fibrose}

Retinal branch vein occlusion 
$7 \begin{array}{llll}\text { Male } & \text { CF } & 6 / 36 & \text { Hypertension }\end{array}$
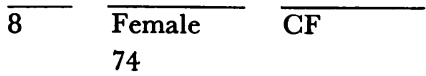

$6 / 9$ 74

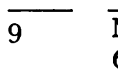

Male
60

$\overline{\mathrm{CF}}$

10

$\overline{\text { Female }}$
70

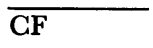

$6 / 60$

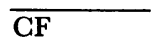

I I

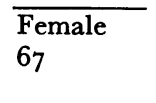

12

Female

60

13

14

64

I 5

Female

67

$\overline{\text { Female }}$
65

Female

64

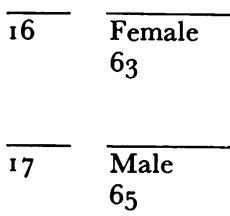

$\overline{6 / 36}$

$6 / 24$

$\overline{6 / 60}$

$6 / 9$

$\overline{6 / 60}$

$\overline{6 / 24}$

$6 / 9$

$/ 9$

$6 / 9$

$\overline{3 / 60}$

$6 / 60$

CF

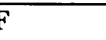

$6 / 60$

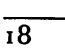

Male

$\overline{6 / 3^{6}}$

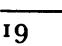

Female

75

20 $\overline{\text { Female }}$
76
Hypertension

Left ventricular hypertrophy

Hypertension with evidence of myocardial ischaemia on electrocardiogram

Previous myocardial infarct

Died as a result of a cerebrovascular accident

Hypertension

Hypertension

Two previous cerebrovascular accidents

$\overline{\text { Died as a result of a myocardial }}$ infarct

$\overline{\text { Hypertension and cardiomegaly }}$

Diabetes mellitus

Elevated serum cholesterol and triglycerides

Lipoprotein electrophoresis Type IV

Elevated serum cholesterol and triglycerides

Lipoprotein electrophoresis Type II B

Hypertension

Elevated serum cholesterol and triglycerides

Lipoprotein electrophoresis Type II B

Hypertension

Elevated serum cholesterol and triglycerides

Lipoprotein electrophoresis Type II B

Previous myocardial infarct

Elevated serum cholesterol and triglycerides

Lipoprotein electrophoresis Type II A
Intraretinal haemorrhage

Single macroaneurysm which did not fibrose

Macular artery occlusion

Subretinal haemorrhage

Single macroaneurysm which fibrosed

Subretinal scarring and pigment epithelial changes

Intraretinal haemorrhage with blood persisting at macula

Two macroaneurysms one of which fibrosed and other remains patent

Second order retinal branch vein occlusion

Preretinal haemorrhage

Single aneurysm which fibrosed

Preretinal traction membrane at the macula

Intraretinal haemorrhage

Single macroaneurysm which fibrosed

Intraretinal haemorrhage

Single macroaneurysm which did not fibrose

Preretinal haemorrhage

Single macroaneurysm which fibrosed

Subretinal haemorrhage

Single macroaneurysm

Subretinal scar tissue

Macular oedema and exudates

Single leaking aneurysm

Macular oedema and exudates

Single leaking aneurysm

Macular oedema and exudates

Single leaking aneurysm which fibrosed and another aneurysm which did not leak

Second order retinal branch vein occlusion

Macular oedema and exudates

Five leaking aneurysms

Macular oedema and exudates

Single leaking aneurysm and another fibrosed aneurysm on an occluded artery

Macular oedema and exudates

Single leaking aneurysm which fibrosed 
frequently deficient or ruptured and similar changes in retinal macroaneurysms could account for staining of the aneurysmal wall and leakage of dye on fluorescein angiography.

Macroaneurysms presented with visual loss either as a result of aneurysmal rupture and macular haemorrhage or of aneurysmal leakage causing macular oedema.

Intraretinal haemorrhage was typically dense but tended to absorb uneventfully with a return to normal vision in weeks or months. The patients with incomplete visual recovery after absorption of the haemorrhage had secondary morphological changes at the macula which were sufficient to account for the visual loss. In none of these patients could visual loss be attributed directly to intraretinal haemorrhage.

Subretinal haemorrhage occurred in a minority of patients, presumably when an aneurysm ruptured through the outer retinal layers and blood was forced into the subretinal space. This resulted in the appearance of a raised dark lesion with overlying intraretinal haemorrhage simulating a neoplasm or a subretinal haemorrhage due to a disciform macular degeneration. Resolution of the subretinal haemorrhage revealed a dense white scar directly under the artery and this was similar in appearance to a fibrosed disciform lesion. However, the changes in the overlying artery indicated the origin of the lesion, as did the absence of subretinal neovascular tissue on fluorescein fundus angiography.

In the 6 patients who presented with macular oedema, fluorescein angiography established that diffuse leakage occurred through the aneurysmal wall indicating the source of oedema fluid and intraretinal exudates. Leakage also occurred from dilated retinal capillaries both in the retina surrounding the macroaneurysm and at the macula, which persisted even in the 2 patients in whom the aneurysm fibrosed. The poorer visual prognosis with macular oedema appeared to be related partly to the continuing leakage caused by delayed closure of the macroaneurysm and partly to the failure of the macular capillaries to return to their normal state when closure of the aneurysm did occur.

Previous reports have implied that the visual prognosis with a retinal macroaneurysm is good and in the patients we have studied the results confirm this view when visual loss was caused by haemorrhage. On the other hand, in patients with visual loss due to macular oedema, the prognosis appears to be considerably poorer. It should be emphasized that macular oedema accounted for loss of vision in onethird of the patients in the series.

These findings are relevant to management. Having recorded spontaneous regression of macroaneurysms, Robertson (1973) suggested that all patients should be observed and that treatment of the aneurysm should be withheld. In patients with visual loss caused by haemorrhage this would appear to be correct. However, patients with macular oedema may be treated successfully, as was illustrated by Hudomel and Imre (1973) who described a patient in whom an aneurysm was caused to close by photocoagulation with subsequent recovery of central vision. The good visual result in their case was dependent upon the structural integrity of the macula and if treatment is indicated it should be given early before exudates cause permanent macular damage.

\section{Summary}

Twenty patients with retinal macroaneurysms were examined and observed for at least 9 months. All these patients were elderly and had evidence of hypertension or systemic vascular disease. Nineteen patients presented with loss of central vision and one patient was asymptomatic. Visual loss was due to macular haemorrhage in 13 patients and macular oedema in 6 . Whereas the visual prognosis in patients with haemorrhage was good it was considerably poorer in the patients with macular oedema.

The authors wish to acknowledge the photographic expertise of Mr K. S. Sehmi and the secretarial assistance of Mrs M. Nurse

\section{References}

Ballantyne, A. J. (1937) Trans. ophthal. Soc. U.K., 57, 301

COLE, F. M., and yates, P. O. (1967) J. Path., 93, 393

FERNANDEZ, F. м. (1920) Amer. J. Ophthal., 3, 641

hUDOMEL, J., and imRe, G. (1973) Acta ophthal. (Kbh.), 51, 633

JENNINGS, J. E. (1918) Ibid., 1, 12

LEBER, T. (1915) 'Graefe-Saemisch-Hess Handbuch der gesamter Augenheilkunde', 2nd ed., vol. 7, p. 20. Englemann, Leipzig

LeISHMan, R. (1957) Brit. F. Ophthal., 41, 641

PRINGLE, J. A. (1917) Ibid., $\mathbf{x}, 87$

raehlmann, E. (1889) Klin. Mbl. Augenheilk., 27, 203

(1902) Z. Augenheilk., 7, 425

REIMAR, M. (1899) Arch. Augenheilk., 38, 209

ROBertson, D. M. (1973) Trans. Amer. Acad. Ophthal. Otolaryng., 77, 55

RUSSELL, R. W. ROSS (1963) Brain, 86, 425

shults, W. T., and swan, K. c. (1974) Amer. F. Ophthal., 77, 304 